\title{
Genotyping of Sex Hormone-Related Pathways in Benign and Malignant Human Prostate Tissues: Data of a Preliminary Study
}

\author{
Carmela Rita Balistreri,' Calogero Caruso,' Giuseppe Carruba,,2 \\ Vitale Miceli, ${ }^{1,2}$ and Giuseppina Candore ${ }^{1}$
}

\begin{abstract}
Prostate cancer (PCa) is a major health issue in Westernized countries, representing a common cause of morbidity and mortality in the elderly male population. Endogenous sex steroids, along with environmental factors (notably diet) and host immune and inflammatory responses, are likely to cooperate in the pathogenesis of the disease. Based on the assumption that a complex endocrine-inflammatory-immune interaction is primarily implicated in human PCa, we have investigated the interplay between sex steroids and inflammation in development and growth of human PCa. To this end, we have assessed nine functional single nucleotide polymorphisms (SNP)s of five genes involved in sex hormone-related pathways in both hyperplastic and malignant human prostate tissues, as well as in matched controls and in a "supercontrol" group composed of male Sicilian centenarians. In particular, the following genes were investigated: AR-OMIM313700, SRD5A2-NM-000348, CYP19-NM-031226, ERS1-NM-001122742, ERS2-NM-001040276. A significant association with prostate cancer was found in seven out of the nine SNPs considered. Although this is a preliminary study and larger investigations are needed to confirm the role of these genes in PCa development and/or progression, our data might provide an experimental basis to develop additional or alternative strategies for prevention and treatment of PCa.
\end{abstract}

\section{Introduction}

$S$ EX STEROID HORMONES are generally believed to play a critical role in the complex pathophysiology of human PCa (Caruso et al., 2009; Ellem and Risbridger, 2010; Ricke et al., 2007). Androgens are primarily responsible for development and function of human prostate gland, as well as for the maintenance of homeostasis of prostate tissues in the adulthood. The major prostatic androgens are the testosterone and its derivative dihydrotestosterone, produced locally through the $5 \alpha$-reductase enzyme. Most of their effects are mediated by binding to androgen receptors (AR). Androgens also represent well-established risk factors for development and progression of benign and malignant disorders of prostate gland (Ricke et al., 2007).

Today there is accumulating evidence suggesting that estrogens play a crucial role in both normal and diseased human prostate (Carruba, 2007; Ellem and Risbridger, 2009, 2010; McPherson et al., 2008). In particular, a combined action of androgens and estrogens and their balance appear to be critically important in maintaining prostate health and tissue homeostasis. An alteration of this balance has been recently implicated in the development of both benign and malignant diseases, including PCa (Ellem and Risbridger, 2009, 2010).

Aging men have unchanged or increased circulating levels of estradiol, as opposed to the decline of plasmatic testosterone. Estrogen production is maintained through aromatization of adrenal androgens driven by the aromatase enzyme, especially in peripheral adipose tissue (Ellem and Risbridger, 2010). In normal prostate gland, the aromatase enzyme is expressed within the stroma, while the malignant prostate show an aberrant aromatase expression in the epithelial compartment (Ellem and Risbridger, 2010). This withdraws circulating testosterone and results in a significant reduction of plasma testosterone to estradiol ratio that has been associated to an increased risk of developing PCa (Carruba, 2007).

The estrogen role in human prostate is further complicated by the differential expression and activity of the two estrogen receptors (ER), $\alpha$ and $\beta$ (Ellem and Risbridger, 2009, 2010). A sustained activation of ER $\alpha$ may eventually lead to an aberrant proliferation, inflammation and to development of premalignant lesions. In contrast, ER $\beta$ appears to have

\footnotetext{
${ }^{1}$ Immunosenescence Group, Department of Pathobiology and Medical and Forensic Biotechnologies, University of Palermo, Palermo, Italy

${ }^{2}$ Experimental Oncology, Department of Oncology, ARNAS-Civico, Palermo, Italy.
} 
antiproliferative effects and to exert a protective role against prostate carcinogenesis (Ellem et al., 2009; Ellem and Risbridger, 2009, 2010).

Despite the above evidence, many epidemiologic studies have failed to show a significant association between circulating sex steroids and prostate cancer risk (Crawford, 2009; Plaza and Giovannucci, 2004). Undoubtedly, several issues related to measurement of plasma steroids, both androgens and estrogens, should be considered to explain this large inconsistency of data. However, the ethnic variability and the heterogeneity of genetic background among the individuals may well have a major impact. In particular, single nucleotide polymorphisms (SNPs) of genes involved in both metabolism and action of steroid hormones may be primarily implicated. An association between PCa risk and SNPs of genes whose products are involved in sex hormone-related steroid pathways has been observed (Chae et al., 2009; Cussenot et al., 2007; Dianat et al., 2009; Huhtaniemi et al., 2010; Mononen and Schleutker, 2009).

Based on the hypothesis that both individual and combined variations in genes that govern local bioavailability and action of sex steroids can modify the individual susceptibility to PCa, we have investigated nine selected SNPs of five genes $(A R-$ OMIM313700, SRD5A2-NM 000348, CYP19-NM-031226, ERS1-NM-001122742. ERS2-NM-001040276) involved in sexrelated hormone pathways, comparing subjects having hyperplastic and malignant prostate, healthy controls, and male centenarians from Sicily. This latter represents a supercontrol group, consisting of "exceptional individuals" who have been able to escape major common age-related diseases, including cancer (Cevenini et al., 2008; Imyanitov, 2009).

\section{Subjects and Methods}

\section{Patients and controls}

The study included 50 Sicilian patients having hyperplastic $(32 \%)$ and malignant prostate $(68 \%)$ lesions recruited at the time of diagnosis (age range: 60-80 years). Controls were 47 healthy male Sicilians according to their clinical history and blood tests. A second control group consisted of 44 male centenarians ( $>99$ years), whose age was confirmed from records at the city hall and/or church registries. No cancer or other age-related diseases were clinically detectable in the centenarians, although some had reduced auditory and visual acuity. Because immigration and intermarriage have historically been rare in the last hundred years, the ethnicity of all participants was established by all four grandparents having been born in Sicily. The study received approval from local ethic committees and all participants gave their written informed consent.

\section{Genotyping}

The study material consisted of DNA samples. The DNA samples of both hyperplastic and cancer cases were obtained from prostate tissue biopsies placed into a suitable volume of RNA-later (RNA Stabilization Reagent, Applied Biosystems, Foster City, CA, USA) to avoid RNA degradation. The DNA samples of the two control groups were extracted from peripheral blood using salting out method (Miller et al., 1998). Genomic DNA and total RNA were purified simultaneously from each sample using an All-Prep DNA/RNA Mini Kit
(Qiagen, Dusseldorf, Germany). Samples were genotyped for nine SNPs of the selected genes, as reported in Table 1. For genotyping, the procedure used was based on the Restriction Fragment-Length Polymorphism-PCR (RFLP-PCR), cleavage with specific restriction enzymes and separation of DNA fragments by electrophoresis, as described in literature data.

\section{Statistics}

Allelic and genotypic frequencies were evaluated by gene count. The data were tested for the goodness of fit between the observed and expected genotype frequencies, according to Hardy-Weinberg equilibrium, by chi-square test. Significant differences in frequencies among the three groups were calculated by $\chi^{2}$ (by $3 \times 3,3 \times 2$, and $2 \times 2$ tables, where appropriate).

\section{Results}

When comparing the genotype distribution and allele frequencies of the nine SNPs selected in the three cohorts of subjects, significant differences were observed for the following SNPs: AR +211G/A, SRD5A2 A49T, CYP19Arg264Cys, CYP19 C1558T, ERS1 351A/G, ERS1 397T/C, ERS2 1082G/A (see Tables 2 and 3, respectively).

As illustrated in the Table 2, significant differences were found ( $p=0.01$, by chi-square test, $3 \times 3$ table) in the genotype distribution of AR $+211 \mathrm{G} / \mathrm{A}$ SNP among the three groups. Significant differences were also observed between patients and matched controls $(p=0.04)$, and between patients and centenarians $(p=0.03)$. In addition, a high frequency of the AR $+211 \mathrm{~A}$ allele expression was found in the three groups ( $p=0.0009$ by chi-square test with Yates's correction, $2 \times 3$ table), and in patients respect to matched controls and centenarians ( $p=0.005$ and $p=0.003$, respectively, by chi-square test with Yates's correction, $2 \times 2$ table) (Table 3 ).

Concerning the two SNPs (A49T and V89L) of the gene encoding the $5 \alpha$-reductase enzyme (SRD5A2), significant differences were observed in genotype distribution of SRD5A2 A49T among the three groups $(p=0.000008)$ (Table 2). Significant differences were also revealed between patients and matched controls ( $p=0.0003)$, and between patients and centenarians $(p=0.00003)$ (Table 2). Accordingly, an overexpression of SRD5A2 49T allele was evidenced in the three groups ( $p=0.0000009$ by chi-square test with Yates's correction, $2 \times 3$ table), and in patients with respect to both matched controls and centenarians ( $p=0.0000001$, by chi-square test with Yates's correction, $2 \times 2$ table) (Table 3 ).

Concerning the three SNPs selected of the aromataseCYP19 gene, significant differences were revealed in genotype distribution of CYP19Arg264Cys among the three groups $(p=0.01)$ (Table 2). A significant difference was also observed between patients and centenarians $(p=0.005$ by chi-square test, $3 \times 2$ table) (Table 2). As expected, an overexpression of the CYP19-264Cys allele was observed among the three groups ( $p=0.004$ by chi-square test with Yates's correction, $2 \times 3$ table) and in patients respect to centenarians $(p=0.001$ by chi-square test with Yates's correction, $2 \times 2$ table) (Table 3 ). Furthermore, the analysis revealed that the genotype distribution of the CYP19-C1558T allele was significantly different among three groups ( $p=0.003$ by chi-square test, $3 \times 3$ table), and between patients and centenarians $(p=0.005$ by chisquare test, $3 \times 2$ table) (Table 2 ). Accordingly, the allele fre- 
Table 1. Genes (Accession Number), SNPs (Accession Number), and Substitutions Investigated in the Study

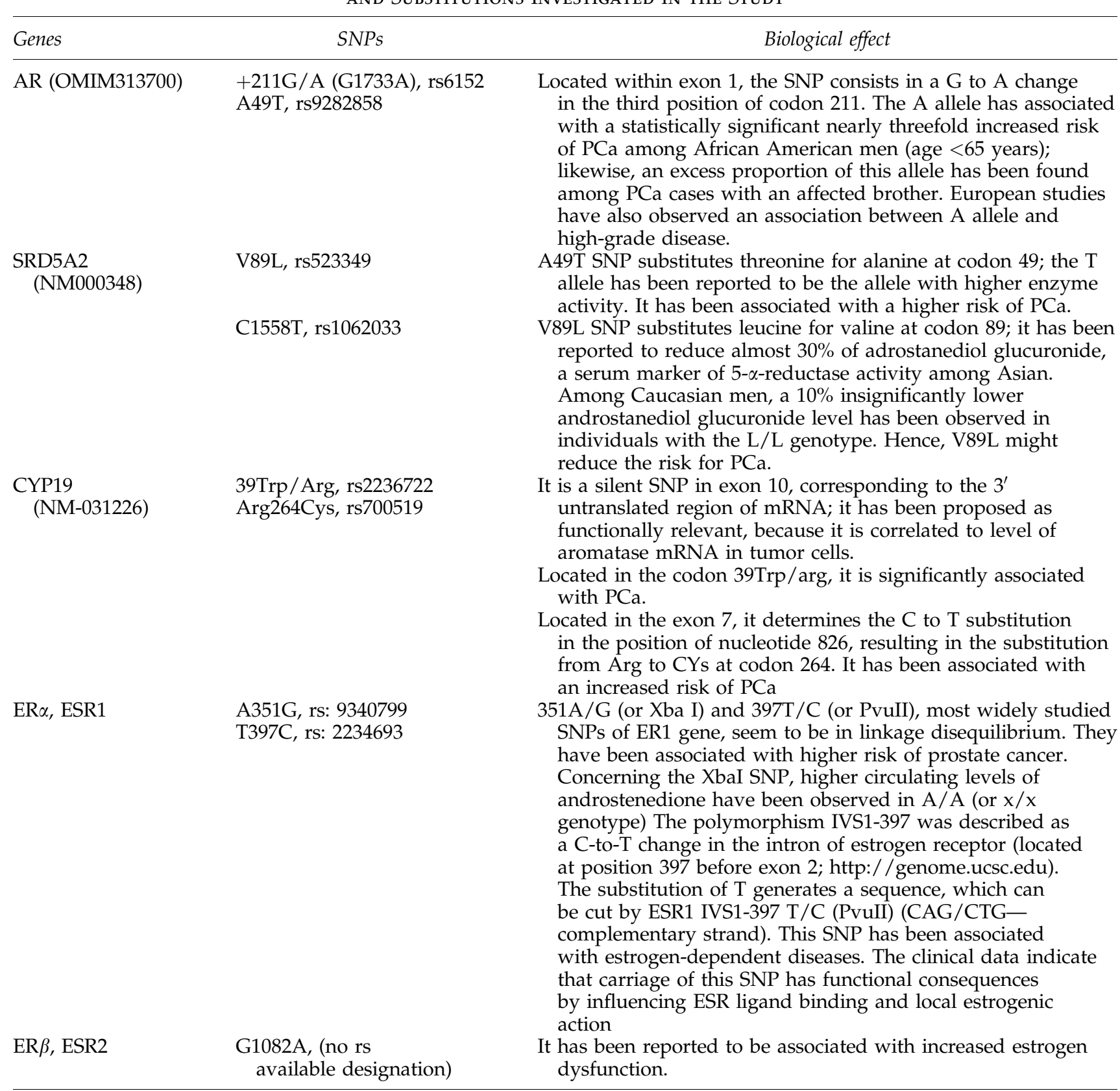

quencies of CYP19 C1558T SNP were significantly distributed among three cohorts ( $p=0.007$ by chi-square test with Yates's correction, $2 \times 3$ table) and between patients and centenarians ( 0.001 by chi-square test with Yates's correction, $2 \times 2$ table) (Table 3). No significant differences both in the genotype distribution and allele frequency of CYP19-39Trp/Arg among the three cohorts were evidenced (data no shown).

As reported in Table 2, significant differences were also obtained in genotype distributions and allele frequencies of ERS1-351A/G and -397T/C SNPs. In particular, significant differences were observed in the genotype distribution of ERS1-351A/G among the three groups $(p=0.001)$, between patients and matched controls $(p=0.03)$ and between patients and centenarians $(p=0.0009)$. Accordingly, an over- expression of the ERS1-351G allele was observed among the three groups ( $p=0.0001$ by chi-square test with Yates's correction, $2 \times 3$ table), in patients with respect to centenarians ( $p=0.0002$ by chi-square test with Yates's correction, $2 \times 2$ table) and between patients and matched controls $(p=0.006$ by chi-square test with Yates's correction, $2 \times 2$ table) (Table 3 ). The genotype distribution of ERS1-397T/C was significantly different among the three groups ( $p=0.01$ by chi-square test, $3 \times 3$ table), and between patients and centenarians ( $p=0.005$ by chi-square test, $3 \times 2$ table) (Table 2 ). Hence, the allele frequencies were significantly distributed among three cohorts $(p=0.004$ by chi-square test with Yates's correction, $2 \times 3$ table) and between patients and centenarians ( $p=0.001$ by chi-square test with Yates's correction, $2 \times 2$ table) (Table 3 ). 
Table 2. Genotype Distribution of SNPs of AR, SRD5A2, CYP19, ERS1, And ERS2 Genes in 50 Hyperplastic and Malignat Cases, 47 Matched Controls, and 44 Centenarians

\begin{tabular}{|c|c|c|c|c|c|c|c|}
\hline SNPs & Genotypes & $\begin{array}{l}\text { Cases } \\
\mathrm{N} \%\end{array}$ & $\begin{array}{c}\text { Matched } \\
\text { controls N \% }\end{array}$ & $\begin{array}{c}\text { Centenarians } \\
\mathrm{N} \%\end{array}$ & $\begin{array}{c}P 1^{a} \\
(3 \times 3 \text { table })\end{array}$ & $\begin{array}{c}P 2^{b} \\
(3 \times 2 \text { table })\end{array}$ & $\begin{array}{c}P 3^{c} \\
(3 \times 2 \text { table })\end{array}$ \\
\hline \multirow[t]{6}{*}{$+211 \mathrm{G} / \mathrm{A}-\mathrm{AR}$} & \multirow[t]{2}{*}{ GG } & 39 & 44 & 42 & \multirow[t]{6}{*}{0.01} & \multirow[t]{6}{*}{0.04} & \multirow[t]{6}{*}{0.03} \\
\hline & & $78 \%$ & $93.6 \%$ & $95.4 \%$ & & & \\
\hline & \multirow[t]{2}{*}{ GA } & 6 & 3 & 2 & & & \\
\hline & & $12 \%$ & $6.4 \%$ & $4.6 \%$ & & & \\
\hline & \multirow{2}{*}{$\mathrm{AA}$} & 5 & 0 & 0 & & & \\
\hline & & $10 \%$ & $0 \%$ & $0 \%$ & & & \\
\hline \multirow[t]{6}{*}{ A49T- SRD5A2 } & \multirow{2}{*}{$\mathrm{A} 49 \mathrm{~A}$} & 21 & 38 & 37 & \multirow[t]{6}{*}{0.000008} & \multirow[t]{6}{*}{0.0003} & \multirow[t]{6}{*}{0.00003} \\
\hline & & $42 \%$ & $80 \%$ & $84 \%$ & & & \\
\hline & \multirow{2}{*}{$\mathrm{A} 49 \mathrm{~T}$} & 11 & 5 & 6 & & & \\
\hline & & $22 \%$ & $11 \%$ & $14 \%$ & & & \\
\hline & \multirow{2}{*}{$\mathrm{T} 49 \mathrm{~T}$} & 18 & 4 & 1 & & & \\
\hline & & $36 \%$ & $9 \%$ & $2 \%$ & & & \\
\hline \multirow{6}{*}{ Arg264Cys-CYP19 } & \multirow[t]{2}{*}{ Arg264Arg } & 37 & 41 & 43 & \multirow[t]{6}{*}{0.01} & \multirow[t]{6}{*}{ NS } & \multirow[t]{6}{*}{0.005} \\
\hline & & $74 \%$ & $87 \%$ & $98 \%$ & & & \\
\hline & \multirow[t]{2}{*}{ Arg264Cys } & 11 & 6 & 1 & & & \\
\hline & & $22 \%$ & $13 \%$ & $2 \%$ & & & \\
\hline & \multirow[t]{2}{*}{ Cys264Cys } & 2 & 0 & 0 & & & \\
\hline & & $4 \%$ & $0 \%$ & $0 \%$ & & & \\
\hline \multirow{6}{*}{ С1558T-СYР19 } & \multirow{2}{*}{ C1558C } & 35 & 39 & 42 & \multirow{6}{*}{0.003} & NS & 0.005 \\
\hline & & $70 \%$ & $83 \%$ & $95 \%$ & & & \\
\hline & C1558T & 13 & 7 & 2 & & & \\
\hline & & $26 \%$ & $15 \%$ & $5 \%$ & & & \\
\hline & $\mathrm{T} 1558 \mathrm{~T}$ & 2 & 1 & 0 & & & \\
\hline & & $4 \%$ & $2 \%$ & $0 \%$ & & & \\
\hline 351A/G-ERS1 & 351A/A & 34 & 42 & 43 & 0.001 & 0.03 & 0.0009 \\
\hline & & $68 \%$ & $89 \%$ & $98 \%$ & & & \\
\hline & $351 \mathrm{~A} / \mathrm{G}$ & 13 & 4 & 1 & & & \\
\hline & & $26 \%$ & $9 \%$ & $2 \%$ & & & \\
\hline & $351 G / G$ & 3 & 1 & 0 & & & \\
\hline & & $6 \%$ & $2 \%$ & $0 \%$ & & & \\
\hline 397T/C-ERS1 & $397 \mathrm{~T} / \mathrm{T}$ & 37 & 41 & 43 & 0.01 & NS & 0.005 \\
\hline & & $74 \%$ & $87 \%$ & $98 \%$ & & & \\
\hline & $397 \mathrm{~T} / \mathrm{C}$ & 11 & 6 & 1 & & & \\
\hline & & $22 \%$ & $13 \%$ & $2 \%$ & & & \\
\hline & $397 \mathrm{C} / \mathrm{C}$ & 2 & 0 & 0 & & & \\
\hline & & $4 \%$ & $0 \%$ & $0 \%$ & & & \\
\hline 1082G/A-ERS2 & $1082 \mathrm{G} / \mathrm{G}$ & 33 & 45 & 42 & 0.0001 & 0.001 & 0.001 \\
\hline & & $66 \%$ & $96 \%$ & $95 \%$ & & & \\
\hline & $1082 \mathrm{G} / \mathrm{A}$ & 16 & 2 & 2 & & & \\
\hline & & $32 \%$ & $4 \%$ & $5 \%$ & & & \\
\hline & 1082A /A & 1 & 0 & 0 & & & \\
\hline & & $2 \%$ & $0 \%$ & $0 \%$ & & & \\
\hline
\end{tabular}

All genotypes were in Hardy-Weinberg equilibrium.

$\mathrm{P}^{\mathrm{a}}=$ significance values calculated by chi-square test, analyzing the data of these SNPs among the three groups.

$\mathrm{P}^{\mathrm{b}}$ = significance values calculated by chi-square test, analyzing the data of these SNPs between patients and age-matched controls.

$\mathrm{P}^{\mathrm{C}}=$ significance values calculated by chi-square test, analyzing the data of these SNPs between patients and centenarians.

Concerning the ERS2-1082G/A SNP, significant differences were also found in genotype distribution of among the three groups $(p=0.0001$ by chi-square test, $3 \times 3$ table), between patients and matched controls $(p=0.001$ by chi-square test, $3 \times 2$ table) and between patients and centenarians ( $p=0.001$ by chi-square test, $3 \times 2$ table). As a consequence, ERS2 1082 A allele was overexpressed among the three groups $(p=0.00005$ by chi-square test with Yates's correction, $2 \times 3$ table), in patients respect to centenarians $(p=0.001$ by chi-square test with Yates's correction, $2 \times 2$ table) and between patients and matched controls ( $p=0.006$ by chi-square test with Yates's correction, $2 \times 2$ table) (Table 3).
In our study the hyperplastic (16) and malignant (34) cases were included in the same group, because the analysis of the data in the separated cohorts (hyperplastic and malignant cases) compared to two control groups did not demonstrate any difference.

In summary, the alleles associated with increased PCa risk were overrepresented in patients compared to healthy men and to centenarians.

\section{Discussion and Conclusion}

The molecular pathology of PCa is intricate. Endogenous sex steroids along with environmental factors (e.g., diet) and 
SEX HORMONE-RELATED PATHWAYS IN HUMAN PROSTATE

Table 3. Allele Frequencies of SNPs of AR, SRD5A2, CYP19, ERS1, and ERS2 Genes in 50 Hyperplastic and Malignat Cases, 47 Matched Controls, and 44 Centenarians

\begin{tabular}{|c|c|c|c|c|c|c|c|}
\hline SNPS & Genotypes & $\begin{array}{l}\text { Cases } \\
\mathrm{N} \%\end{array}$ & $\begin{array}{c}\text { Matched } \\
\text { controls N \% }\end{array}$ & $\begin{array}{c}\text { Centenarians } \\
\mathrm{N} \%\end{array}$ & $\begin{array}{c}P 1^{a} \\
(2 \times 3 \text { table })\end{array}$ & $\begin{array}{c}P 2^{b} \\
(2 \times 2 \text { table })\end{array}$ & $\begin{array}{c}P 3^{c} \\
(2 \times 2 \text { table })\end{array}$ \\
\hline \multirow[t]{3}{*}{$+211 \mathrm{G} / \mathrm{A}-\mathrm{AR}$} & A211 & 84 & 91 & $\begin{array}{c}86 \\
872 \%\end{array}$ & \multirow[t]{3}{*}{0.0009} & \multirow[t]{3}{*}{0.005} & \multirow[t]{3}{*}{0.003} \\
\hline & \multirow{2}{*}{$211 G$} & $\begin{array}{c}84 \% \\
16\end{array}$ & $\begin{array}{c}96.8 \% \\
3\end{array}$ & $\begin{array}{c}97.2 \% \\
2\end{array}$ & & & \\
\hline & & $16 \%$ & $3.2 \%$ & $2.8 \%$ & & & \\
\hline \multirow[t]{4}{*}{ A49T- SRD5A2 } & \multirow[t]{2}{*}{ A49 } & 53 & 81 & 80 & \multirow[t]{4}{*}{0.0000009} & \multirow{4}{*}{0.00000001} & \multirow[t]{4}{*}{0.00000001} \\
\hline & & $53 \%$ & $86 \%$ & $90 \%$ & & & \\
\hline & \multirow{2}{*}{$49 \mathrm{~T}$} & 47 & 13 & 8 & & & \\
\hline & & $47 \%$ & $14 \%$ & $10 \%$ & & & \\
\hline \multirow[t]{4}{*}{ Arg264Cys-CYP19 } & \multirow[t]{2}{*}{ Arg264 } & 85 & 88 & 87 & \multirow[t]{4}{*}{0.004} & \multirow[t]{4}{*}{ NS } & \multirow[t]{4}{*}{0.001} \\
\hline & & $85 \%$ & $94 \%$ & $98 \%$ & & & \\
\hline & \multirow[t]{2}{*}{ 264Cys } & 15 & 6 & 1 & & & \\
\hline & & $15 \%$ & $6 \%$ & $2 \%$ & & & \\
\hline \multirow[t]{4}{*}{ С1558T-СYР19 } & \multirow[t]{2}{*}{ C1558 } & 83 & 85 & 86 & \multirow[t]{4}{*}{0.007} & \multirow[t]{4}{*}{ NS } & \multirow[t]{4}{*}{0.001} \\
\hline & & $83 \%$ & $90 \%$ & $98 \%$ & & & \\
\hline & \multirow[t]{2}{*}{$1558 \mathrm{~T}$} & 17 & 9 & 2 & & & \\
\hline & & $17 \%$ & $10 \%$ & $2 \%$ & & & \\
\hline \multirow[t]{4}{*}{ 351A/G -ERS1 } & \multirow[t]{2}{*}{ A351 } & 71 & 88 & 86 & \multirow[t]{4}{*}{0.0001} & \multirow[t]{4}{*}{0.006} & \multirow[t]{4}{*}{0.0002} \\
\hline & & $71 \%$ & $94 \%$ & $98 \%$ & & & \\
\hline & \multirow[t]{2}{*}{$351 G$} & 19 & 6 & 2 & & & \\
\hline & & $19 \%$ & $6 \%$ & $2 \%$ & & & \\
\hline \multirow[t]{4}{*}{ 397T/C-ERS1 } & T397 & 85 & 88 & 87 & 0.004 & NS & 0.001 \\
\hline & & $85 \%$ & $94 \%$ & $98 \%$ & & & \\
\hline & $397 C$ & 15 & 6 & 1 & & & \\
\hline & & $15 \%$ & $6 \%$ & $2 \%$ & & & \\
\hline 1082G/A-ERS2 & G1082 & 82 & 92 & 86 & 0.00005 & 0.006 & 0.001 \\
\hline & & $82 \%$ & $98 \%$ & $98 \%$ & & & \\
\hline & $1082 \mathrm{~A}$ & 18 & 2 & 2 & & & \\
\hline & & $18 \%$ & $2 \%$ & $2 \%$ & & & \\
\hline
\end{tabular}

$\mathrm{P} 1^{\mathrm{a}}=$ significance values calculated by chi-square test, analyzing the data of these SNPs among the three groups.

$\mathrm{P} 2^{\mathrm{b}}=$ significance values calculated by chi-square test, analyzing the data of these SNPs between patients and age-matched controls. $\mathrm{P}^{\mathrm{C}}=$ significance values calculated by chi-square test, analyzing the data of these SNPs between patients and centenarians.

host immune and inflammatory responses are likely to cooperate in the pathogenesis of this neoplastic disease (Caruso et al., 2009; De Marzo et al., 2007).

Based on this assumption, we have analyzed the association between $\mathrm{PCa}$ and nine functional SNPs of the AR, SRD5A2, CYP19, ERS1 e ERS2 genes involved in sex hormone pathways. Our results suggest the potential association of seven out of nine SNPs with PCa. They also reveal that most of the selected alleles are underrepresented in centenarians, used in our study as an additional supercontrol group of "exceptional individuals" free of major common age-related diseases, including cancer (Cevenini et al., 2008; Imyanitov, 2009).

Our data also imply that alleles associated with age-related diseases, including $\mathrm{PCa}$, are not prominent in the genetic profile favouring longevity, as indicated in our previous studies (Candore et al., 2007a, 2007b). Based on this evidence, one could speculate that the genes selected in our study may function in an antagonistically pleiotropic manner. They exert a beneficial role in younger age maintaining growth and homeostasis of the prostate gland, while they play a detrimental role producing an aberrant cell proliferation, inflammation and the development of premalignant and malignant lesions later in life.

The mechanisms underpinning the putative role of the selected alleles in the development and/or progression of PCa during the aging process, however, remain unknown. Larger studies are needed to confirm the findings of this preliminary report and to get insights into relevant mechanisms, with special emphasis on local metabolism and action of either androgens or estrogens. It should be noted that circulating sex steroids cannot be considered representative of their intraprostatic levels that strictly depends upon expression and activity of key enzymes governing local metabolism and biotransformation (Carruba, 2007). In this respect, the appraisal of steroid enzymes (such as aromatase and 5- $\alpha$ reductase) and receptors (such as $\mathrm{AR}, \mathrm{ER} \alpha$ and $\mathrm{ER} \beta$ ), that respectively determine metabolic profiles and signaling in both normal and diseased human prostate, is crucially important to associate sex hormone-related pathways and PCa risk. In this framework, our data, although preliminary, might provide an important experimental basis to develop additional or alternative strategies for prevention and treatment of human PCa.

\section{Acknowledgments}

The authors are indebted to Dr. Mario Ferrera, who provided both benign and malignant human prostate biopsies. This work was supported by Italian Ministry of Health grant (molecular mechanisms of stem cancer cell survival control) to G.C. and C.C. V.M. is a PhD student at Pathobiology Course 
of Palermo University (directed by CC) and this article is in partial fulfillment of the requirement for its $\mathrm{PhD}$.

\section{Author Disclosure Statement} xist.

\section{References}

Balistreri, C.R., Carruba, G., Calabrò, M., Campisi, I., Di Carlo, D., Lio, D., et al. (2009). CCR5 proinflammatory allele in prostate cancer risk: a pilot study in patients and centenarians AU1 from Sicily. Ann N Y Acad Sci 1155, 289-292.

Balistreri, C.R., Caruso, C., and Candore, G. (2010a). The role of adipose tissue and adipokines in obesity-related inflammatory

AU2 diseases. Mediators Inflamm. doi: 10.1155/2010/802078

Balistreri, C.R., Caruso, C., Carruba, G., Miceli, V., Campisi, I., Listì, F., et al. (2010b). A pilot study on prostate cancer risk and pro-inflammatory genotypes: pathophysiology and ther-

AU3 apeutic implications. Curr Pharm Des 16, 718-724.

Candore, G., Balistreri, C.R., Caruso, M., Grimaldi, M.P., Incalcaterra, E., Listì, F., et al. (2007a). Pharmacogenomics: a tool to prevent and cure coronary heart disease.Curr Pharm Des 13, 3726-3734.

Candore, G., Balistreri, C.R., Grimaldi, M.P., Listì, F., Vasto, S., Chiappelli, M., et al. (2007b). Polymorphisms of pro-inflammatory genes and Alzheimer's disease risk: a pharmacogenomic approach. Mech Ageing Dev 128, 67-75.

Carruba, G. (2007). Estrogen and prostate cancer: an eclipsed truth in an androgen-dominated scenario. J Cell Biochem 102, 899-911.

Caruso, C., Balistreri, C.R., Candore, G., Carruba, G., ColonnaRomano, G., Di Bona, D., et al. (2009). Polymorphisms of pro-inflammatory genes and prostate cancer risk: a pharmacogenomic approach. Cancer Immunol Immunother 58, 19191933.

Cevenini, E., Invidia, L., Lescai, F., Salvioli, S., Tieri, P., Castellani, G, et al. (2008). Human models of aging and longevity. Expert Opin Biol Ther 8, 1393-1405.

Chae, Y.K., Huang, H.Y., Strickland, P., Hoffman, S.C., and Helzlsouer, K. (2009). Genetic polymorphisms of estrogen receptors alpha and beta and the risk of developing prostate cancer. PLoS One 4, e6523

Crawford, E.D. (2009). Understanding the epidemiology, natural history, and key pathways involved in prostate cancer. Urology 73, S4-S10.

Chrisofos, M., Papatsoris, A.G., Lazaris, A., and Deliveliotis, C. (2007). Precursor lesions of prostate cancer Crit Rev Clin Lab AU4 Sci. 44, 243-270.

Cussenot, O., Azzouzi, A.R., Nicolaiew, N., Fromont, G., Mangin, P., Cormier, L, et al. (2007). Combination of polymorphisms from genes related to estrogen metabolism and risk of prostate cancers: the hidden face of estrogens. J Clin Oncol 25, 3596-3602.

De Marzo, A.M., Platz, E.A., Sutcliffe, S., Xu, J., Grönberg, H., Drake, C.G., et al. (2007). Inflammation in prostate carcinogenesis. Nat Rev Cancer 7, 256-269

Dianat, S.S., Margreiter, M., Eckersberger, E., Finkelstein, J., Kuehas, F., Herwig, R., et al. (2009). Gene polymorphisms and prostate cancer: the evidence. BJU Int 104, 1560-1572.
Ellem, S.J., and Risbridger, G.P. (2009). The dual, opposing roles of estrogen in the prostate. Ann N Y Acad Sci 1155, 174186.

Ellem, S.J., and Risbridger, G.P. (2010). Aromatase and regulating the estrogen: androgen ratio in the prostate gland. J Steroid Biochem Mol Biol 118, 246-251.

Ellem, S.J., Wang, H., Poutanen, M., and Risbridger, G.P (2009). Increased endogenous estrogen synthesis leads to the sequential induction of prostatic inflammation (prostatitis) and prostatic pre-malignancy. Am J Pathol 175, 1187-1199.

Esteban, E., Via, M., González-Pérez, E., Santamaría, J., Dugoujon, J.M., Vona, G., et al. (2005). An unexpected wide population variation of the G1733A polymorphism of the androgen receptor gene: data on the Mediterranean region. Am J Hum Biol 17, 690-695.

Huhtaniemi, I.T., Pye, S.R., Holliday, K.L., Thomson, W., O'Neill, T.W., Platt, H., et al. (2010). European Male Aging Study Group. Effect of polymorphisms in selected genes involved in pituitary-testicular function on reproductive hormones and phenotype in aging men. J Clin Endocrinol Metab 95, 1898-1908.

Imyanitov, E.N. (2009). Use of elderly tumor-free subjects as a "supercontrol" for cancer epidemiological studies: pros and cons. Mech Ageing Dev 130, 122-127.

Ma, C.X., Adjei, A.A., Salavaggione, O.E., Coronel, J., Pelleymounter, L., Wang, L., et al. (2005). Human aromatase: gene resequencing and functional genomics. Cancer Res 65, 11071-11082.

McPherson, S.J., Ellem, S.J., and Risbridger, G.P. (2008). Estrogen-regulated development and differentiation of the prostate. Differentiation 76, 660-670.

Miller, S.A., Dykes, D.D., and Polesky, H.F (1998). A simple salting out procedure for extracting DNA from human nucleated cells. Nucleic Acid Res 16, 1215.

Mononen, N., and Schleutker, J. (2009). Polymorphisms in genes involved in androgen pathways as risk factors for prostate cancer. J Urol 181, 1541-1549.

Modugno, F., Weissfeld, J.L., Trump, D.L., Zmuda, J.M., Shea, P., Cauley, J.A., et al. (2001). Allelic variants of aromatase and the androgen and estrogen receptors: toward a multigenic model of prostate cancer risk. Clin Cancer Res 7, 30923096.

Platz, E.A., and Giovannucci, E. (2004). The epidemiology of sex steroid hormones and their signaling and metabolic pathways in the etiology of prostate cancer. J Steroid Biochem Mol Biol 92, 237-253.

Ricke, W.A., Wang, Y., and Cunha, G.R (2007). Steroid hormones and carcinogenesis of the prostate: the role of estrogens. Differentiation 75, 871-882.

Address correspondence to: Dr. Carmela Rita Balistreri Immunosenescence Group Department of Patho-biology and Medical and Forensic Biotechnologies University of Palermo Corso Tukory 211 90134 Palermo, Italy

E-mail: crbalistreri@unipa.it 


\section{AUTHOR QUERY FOR OMI-2010-0128-BALISTRERI_1P}

AU1: Please cite Balistreri et al. 2009 in the text. AU2: Please cite Balistreri et al. 2010a in the text. AU3: Please cite Balistreri et al. 2010b in the text. AU4: Please cite Chrisofos et al. 2007 in the text. AU5: Please cite Esteban et al. 2005 in the text. AU6: Please cite Modugno et al. 2001 in the text. 